\title{
EL “DIVINO MESTIZO” FRENTE A LA MÁQUINA DE GUERRA. MiMESIS HETEROGÉNEA Y SUbJETIVIDAD MigRANTE EN El TIEMPO PRINCIPIA EN XibALbÁ, DE LUIS DE LióN
}

\section{The “Divine Mestizo” versus the War Machine. Heterogeneous Mimesis and Migrant Subjectivity in El tiempo PRincipia en Xibalbá, by Luis de Lión}

\author{
Rodrigo García de la Sienra*
}

DOI: http://dx.doi.org/10.29043/liminar.v19i2.846

Resumen: En este trabajo se lleva a cabo un análisis detallado de la única novela del escritor guatemalteco Luis de Lión. Al tiempo que se establece su carácter de literatura heterogénea (conforme a la terminología de Cornejo Polar), se explica en qué sentido la proveniencia étnica de su autor implica un elemento subversivo respecto a la literatura indigenista y a la "etnoficción". Posteriormente se describe su constitución mimética y se establece la importancia de la subjetividad migrante como parte de la propuesta literaria del autor.

Palabras clave: Luis de Lión, El tiempo principia en Xibalbá, literatura guatemalteca, literatura indígena, subjetividad migrante.

Abstract: This article undertakes a detailed analysis of the only novel by the Guatemalan writer Luis de Lión. The paper establishes the novel's character as heterogeneous literature (in accordance with the terminology of Cornejo Polar), as it discusses how the author's ethnic origin suggests a subversive element with respect to indigenist literature and "ethno-fiction". Further, the novel's mimetic constitution is described and the importance of migrant subjectivity is established as part of the author's intention.

Key words: Luis de Lión, El tiempo principia en Xibalbá, Guatemalan literature, indigenous literature, migrant subjectivity.

\footnotetext{
* Rodrigo García de la Sienra. Doctor en Estudios romances, Universidad de la Sorbona Paris-IV, Francia. Profesor-investigador en el Instituto de Investigaciones Lingüistico-Literarias de la Universidad Veracruzana, México. Temas de especialización: teoría literaria, filosofía y literatura, literatura mexicana e hispanoamericana. Correo electrónico: rodrigo. delasienra@gmail.com. ORCID: https://orcid.org/0000-0002-5204-1731
}

Enviado a dictamen: 25 de septiembre de 2020

Aceptación: 18 de febrero de 2021 


\section{El tiempo principia en Xibalbá, literatura heterogénea}

A unque parcialmente, las condiciones del campo literario en Hispanoamérica han cambiado desde aquel junio de 1972 en el que Luis de Lión (José Luis de León Díaz) firmara su única novela al pie del volcán Hunapú. Pues es indudable que, a pesar de los grandes obstáculos que todavía enfrenta para su difusión y apreciación, la plural vitalidad de las literaturas indígenas del continente goza actualmente de mayor visibilidad y reconocimiento. Dentro de ese contexto, hay quienes consideran El tiempo principia en Xibalbá como un hito fundacional de la literatura indígena contemporánea en Guatemala (Palacios, 2011), y también como un desafío al canon literario latinoamericano en su conjunto (Bubnova, 2002a). Además, el perfil de Luis de Lión en tanto intelectual indígena se define en razón de su abierta militancia política y del terrible sello que le imprimió su desaparición a manos del gobierno de su país en mayo de $1984{ }^{1}$

En este trabajo veremos cómo la subjetividad "indígena" de este escritor cakchiquel resulta un elemento fundamental para la comprensión de El tiempo principia en Xibalbá, sobre todo si se parte del hecho de que, como señala Dante Liano, el tema central de esa novela es, precisamente, la exploración íntima de un "psiquismo maya":

Si los grandes escritores mestizos han presentado válidamente la realidad campesina bajo el signo de la épica, de lo mágico, de lo mítico, y así sucesivamente, De Lion nos la muestra, en cambio, bajo el signo de lo cotidiano, del deseo íntimo, profundo, personal. Nadie había pensado (y tal vez habría parecido una locura) en escribir una novela de la intimidad maya. De Lion nos revela no sólo la intimidad, sino su interpretación del inconsciente de su colectividad. No encontraremos, en él, las grandes hazañas o las sagas familiares que tanto gustan a los escritores y a los lectores de literatura latinoamericana. Él excava en lo profundo de la psiquis, comenzando probablemente por sí mismo, sin concesiones ni pudores (Liano, 2018:73-74).
Es cierto, como aduce Liano, que Luis de Lión "es moderno porque usa todos los instrumentos de la vanguardia", como por ejemplo la fusión surrealista del erotismo y la violencia, la alteración de la sintaxis y la fragmentación narrativa, pero sobre todo por el hecho de que en El tiempo principia en Xibalbá “la fragmentación temporal corresponde a otra fragmentación más íntima: la fragmentación del sujeto narrativo" (Liano, 2018:71). Por su parte, en diálogo directo con estos asertos, Laura Martin señala que quien carece del conocimiento de las formas tradicionales de los idiomas mayas no logra percibir correctamente las peculiaridades del "castellano localizado" empleado por de Lión, y por ende tampoco la retórica expresiva del texto:

Pocos intérpretes han reconocido hasta qué punto el
autor despliega tanto las convenciones retóricas como
estructurales que se ven en la narrativa tradicional
maya. Son las mismas convenciones tradicionales
que se demuestran en forma magisterial en la historia
maya de la creación del mundo, el Popol Vuh. No solo
hay resonancias con el lenguaje, sino también con con-
tenido y temas de esa gran obra. La novela está llena
de imágenes, acciones y actores que nos recuerdan
esa conocida historia. A pesar de que sus imágenes
surrealistas, su línea narrativa no-lineal y su estilo
de narración con tanta frecuencia se analizan como
experimentos pos-modernos, El tiempo principia en Xi-
balbá es de hecho una traducción de formas narrativas
mayas tradicionales. Se traducen a un contexto que
tiene elementos fácilmenteidentificados con la nación
hispanizada donde ahora viven los mayas subordina-
dos. Pero su patrón es el mundo de la creación maya
(Martin, 2005:5).

Mediante un cotejo textual, esta autora procede a documentar las semejanzas (frásticas, semánticas, etcétera) que existen entre El tiempo principia en Xibalbá y el Popol $V u h$, buscando con ello inscribir el texto dentro de una tradición literaria autóctona. ${ }^{2}$ Ahora bien, tal y como ella la concibe, la "traducción" de esta matriz verbal, retórica e incluso cosmogónica maya a los códigos de la "nación hispanizada", se asemeja enormemente a lo 
que Ángel Rama buscaba describir a través de la noción de "transculturación narrativa". Pero esta proximidad conceptual resulta interesante sobre todo por el hecho de que la obra y figura de Luis de Lión plantean una sutil inversión de las coordenadas del "sujeto transcultural": primero, en razón de la legitimidad que confieren a su empresa su proveniencia e identificación étnicas (el escritor se negaba a considerarse un mestizo), ${ }^{3}$ y después por el hecho de que la situación geográfica de la etnia en la que creció no correspondía a las "regiones maceradas aisladamente" a las que aludiera Rama (la región andina de Arguedas, los Altos de Jalisco de Rulfo o el Sertón brasileño de Guimarães Rosa), sino que se trata de una zona que desde épocas tempranas representó un espacio de intenso intercambio lingüístico y cultural.

En realidad, tanto la lectura "vanguardista" como la "maya tradicional" son de igual modo convincentes, pues es precisamente gracias a la confluencia, o mejor aún, a la coexistencia indiscernible de esas distintas vertientes literarias que el texto posee tanta potencia y eficacia. ${ }^{4} Y$ es por ello que debemos resaltar que tanto la tradición literaria indígena a la que pertenece el Popol Vuh como la literatura indigenista en castellano con la que claramente dialoga la novela tienen en común el hecho de ser literaturas heterogéneas, en el sentido que confiere al término Antonio Cornejo Polar. Recordemos que el crítico peruano concibió esa categoría para dar cuenta de "procesos de producción de literaturas en las que se intersectan conflictivamente dos o más universos socio-culturales", con un énfasis particular "en la diversa y encontrada filiación de las instancias más importantes de tales procesos (emisor/discurso-texto/referente/ receptor, por ejemplo)" (Cornejo, 2003:10).

En ese sentido, me parece importante explicitar brevemente las razones por las cuales, sin dejar de ser "literatura indígena", incluso el propio Popol Vuh es ante todo una literatura heterogénea. Aun cuando se trate de un texto proveniente de una tradición de origen prehispánico que probablemente haya tenido alguna clase de sustento mnemotécnico en un códice jeroglífico, es imposible obviar que el manuscrito resguardado en la biblioteca Newberry es un texto colonial que "parece haber sido escrito en caracteres alfabéticos por primera vez a mediados del siglo XVI por uno de los miembros alfabetizados de la nobleza indígena k'iche"' (Sotelo y Craveri, 2017:7).

Además de la existencia de ese "sujeto transcultural" que es el letrado indígena, es evidente que la transcripción alfabética implica una transformación sustancial del texto de tradición oral (u oral-pictográfica) desde el punto de vista de su materialidad significante. Woodruff (2011) destaca el matiz que imprime sobre la lectura la decisión editorial que en su momento tomó Étienne Brasseur de Boubourg de publicar el manuscrito Empiezan las Historias del Origen de los Indios de Esta Provincia de Guatemala (que más tarde se habría de conocer como el Popol Vuh) separadamente del Tratado segundo de todo lo que debe saber un ministro y de la gramática quiché Arte de las tres lenguas, que por su parte Francisco Ximénez había decidido integrar en un mismo volumen. Woodruff insiste en que ese criterio, históricamente relacionado con el horizonte de expectativas del americanismo europeo decimonónico, agudiza nuestra percepción del texto como una "autoetnografía", al tiempo que oblitera el papel que el dominico desempeñó, no solo en tanto copista y traductor, sino sobre todo en tanto editor, es decir, en tanto instancia organizadora del entramado de sentido que alberga y resignifica la transcripción alfabética. La falta de elementos históricos fehacientes en lo que se refiere a la autoría de la transcripción - o, si se prefiere, a la identidad del copista,$-{ }^{5}$ aunada a un análisis filológico de los paratextos (preámbulos, anotaciones, escolios y demás comentarios), permite a este autor plantear la necesidad de considerar a Ximénez como algo más que un copista en sentido estrecho, y plantear una hipótesis que inserta una variable más en el contexto de producción del texto:

En la medida en que, en vez de revelar su fuente, Ximénez invita a sus lectores a inferir lo que deseen respecto al primer folio recto, es plausible que no haya habido tal redacción alfabética entre los indígenas. La alternativa implícita es que él o algún otro misionario hayan llevado a cabo la primera transcripción a partir de una recitación oral. 
En conclusión, el paratexto del manuscrito de Ximénez hace que emerja una nueva dimensión crítica: el Popol Vuh fue parte de un tratado religioso compuesto específicamente para lectores europeos (Woodruff, 2011:104, traducción propia).

No es mi intención suscribir esta hipótesis, ${ }^{6}$ sino mostrar cómo, desde el momento mismo en que se grabó en la materialidad significante de los caracteres latinos y del libro occidental, el relato de raigambre prehispánica quedó inevitablemente inscrito en la esfera de la textualidad heterogénea del documento colonial. Y que, consecuentemente, el Popol Vuh no puede ser hermenéuticamente concebido al margen de las diferentes tradiciones literarias que no solo lo han hecho suyo, sino que incluso han contribuido a conformarlo históricamente (empezando por sus copias y sus numerosas traducciones), por lo que es indispensable tener en cuenta las interacciones e interferencias que se dan entre esas heterogéneas vertientes literarias.

De esta suerte, una vez descartada la posibilidad de atribuir las analogías discursivas entre la novela del intelectual que fue Luis de Lión y la retórica del Popol Vuh a una matriz estrictamente tradicional (es decir desvinculada del arco que parte de las primeras versiones escritas del texto, pasa por la suma de sus traducciones y aterriza en las recreaciones producidas por el indigenismo literario con el que el autor claramente dialoga), estaremos en mejores condiciones para abordar el problema del extrañamiento explícito al que la novela alude, precisamente respecto al libro más representativo de los mayas. En el contexto de la boda de los personajes de Juan Caca y Concepción, el narrador refiere en un tono notablemente irónico:

Recuerdo que fue la misa más larga que había habido hasta entonces, pues para las otras, el padre llegaba con prisa para terminar pronto y sólo se detenía en el sermón por un rato para predicar en contra de los protestantes, de los que no había ni uno en el pueblo; en contra de los liberales y los masones, que eran parecidos a los protestantes, pero de los que nadie conocía ni uno para muestra, y de vez en cuando también en contra de los comunistas, que para la gente del pueblo era como oír hablar de una España lejana y perdida entre el mar o como un libro llamado Popol Vuh (De Lión, 1997:16).

Sin entrar en la problemática del sujeto de la enunciación (¿quién recuerda en este pasaje?), quisiera subrayar que la misma extrañeza que experimenta "la gente del pueblo" respecto a las fantasmagorías típicamente enarboladas por el conservadurismo católico (protestantes, liberales, masones y comunistas), así como respecto a esa entidad vaporosa que resulta ser España, alcanza por igual al libro donde a inicios de la Colonia fuera recogido el relato de los depositarios de la tradición antigua. Esto no debiera sorprender, en la medida en que el extrañamiento del sujeto "indio" respecto de sí mismo es un eje que atraviesa y estructura esta novela de varias maneras, confiriendo una significación particular a su heterogeneidad constitutiva.

Como se mencionó anteriormente, aunque sea claro que El tiempo principia en Xibalbá comparte con la novela indigenista una serie de elementos básicos, como ser un discurso novelesco en castellano que tiene como referente un universo indígena pero que está esencialmente dirigido a un receptor "hispanizado" (o, si se prefiere, "ladino"), debemos insistir en que dicha ecuación se encuentra subvertida en razón de la proveniencia étnica de su autor. Tatiana Bubnova apunta acertadamente respecto a las implicaciones éticas de esta variante que, a diferencia del discurso indigenista y de la etnoficción, en donde la construcción literaria de un mundo interior propio del sujeto indígena se ve obturada por una suerte de imposibilidad constitutiva, la pertenencia de Luis de Lión a la nación maya le confiere la legitimidad intelectual para plantear como una vivencia interna, "en el territorio íntimo del indígena, en el yo de sus personajes campesinos" (Bubnova, 2002b), la escisión y la ruptura radical del horizonte axiológico de la propia sociedad maya contemporánea. De manera que:

[1]eída desde el momento actual, la novela resulta una paráfrasis o una profecía de la posición desgarradora del sujeto de finales del siglo XX. El sujeto 
occidental se ha reservado tradicionalmente el privilegio de la sensibilidad estética e intelectual, cuestionándola en el "indio" aun en el discurso indigenista. Esta posición viene definida ahora por su otro, y su sentir es la rebelión y el caos: así lo plantea Luis de Lión (Bubnova, 2002b:166).

\section{Mimesis heterogénea}

Aun cuando sea evidente que el registro "campesino" del que da cuenta El tiempo principia en Xibalbá es fruto de un trabajo estilístico, y que en esa novela Luis de Lión empleó recursos "mitopoéticos" semejantes a los de la etnoficción, también es visible que "no es por el lado de la inventiva lingüística como Luis de Lión afirma y muestra su identidad indígena" (Bubnova, 2002b:156). Pues el problema estético al que se enfrentó este escritor cakchiquel no era, como en el caso de Juan Rulfo o José María Arguedas, la creación de un lenguaje adecuado para representar literariamente, de manera verosímil, el habla de indígenas y campesinos, sino el de la exploración "sin concesiones" de la propia subjetividad. Esto no significa que la exploración subjetiva esté desvinculada del plano del discurso, sino que, en vez de estar centrados en el léxico y la sintaxis, los recursos miméticos se orientan preferentemente hacia el ámbito de la enunciación, que es un eje para la representación discursiva tanto de los otros como de sí mismo.

Resulta lógico que, si hablamos aquí de un sujeto fragmentado, dicha fragmentación se manifieste también en el plano de la enunciación, no solo en lo concerniente a las personas gramaticales, sino también a la actitud del enunciador frente a su propio enunciado. Cabe enfatizar que a lo largo de toda la novela el narrador exhibe una constante distancia irónica respecto al mundo narrado, y que, aunque por sí sola dicha distancia no bastaría para producir una fragmentación, su coalescencia con una ambigüedad generalizada termina por hacer vacilar el sentido y por producir la fragmentación de la subjetividad.

En ese sentido, la lapidaria frase "La Virgen de Concepción era una puta” (De Lión, 1997:10) resulta central, en tanto que en ella la (des)organización del sentido global del texto pareciera condensarse en su mínima expresión. Se puede decir que la ironía opera a partir del momento en el que el sentido estrictamente antinómico de la cópula transita hacia un ámbito de indecibilidad. O de otro modo: si en un principio las palabras "virgen" y "puta" parecen antónimos, la ironía abre el sentido y nos invita a ir más allá de esa aparente antinomia, aguijoneados por la insidiosa pregunta acerca de las demás posibilidades que recela el enunciado. La ambigüedad no se limita a la indeterminación del sentido de ese enunciado pues, conforme la lectura avanza, se puede corroborar que su carácter oscilatorio se reproduce de una manera todavía más compleja en el nivel superior de la mimesis novelesca. El lector descubrirá en efecto que en la novela "virgen" y "puta" no solo no son antónimos, sino que de hecho ese enunciado se refiere indistintamente a dos entes que, más que antagónicos, resultan ser contrarios complementarios.

La Virgen de Concepción es una efigie vestida "con una ropa simulada de la misma madera" con la que está tallada, con "una tela delgada, apenas gruesa que el escultor iindio?, sí, indio, le había dejado tan sólo para disimular su amor y su odio" (De Lión, 1997:61); y que, una vez vejada y profanada por Pascual Baeza, se anima, habla e incluso cobra rasgos morales, y termina por recibir un trato de "puta" por parte de los hombres del pueblo - "la despojaron de su corona, de su manto, de su vestido y luego la escupieron, la ultrajaron con palabras de puta aquí y puta allá, la machetearon y la tiraron en un rincón con las demás cosas viejas de la iglesia" (1997:76) —. Pero también es Concepción, "la Concha" (en evidente alusión al sexo femenino), la mujer que ha tenido sexo con prácticamente todo el pueblo y cuyo parecido físico con la efigie de madera le permite suplantar doblemente a la imagen mariana: primero, en la fantasía sexual de quienes se acostaban con ella - "era sabroso, riquísimo, gozar seguido ese rito lacrimoso con que ella recibía a los hombres, los hacía soñar como si de verdad estuvieran sobre la auténtica Virgen de Concepción" (1997:13) — y después, sencillamente porque es abiertamente coronada y venerada en lugar de la efigie - - procedieron a ponerle el vestido, el manto, la corona a ella, la nueva virgen, la colocaron 
sobre el anda, la adornaron con luces de huesos, con flores de huesos, con aserrín de huesos y la sacaron en procesión" (1997:76)—.

Si desde la óptica doctrinaria lo que caracteriza a la Virgen de Concepción es, como su nombre lo indica, haber concebido sin previamente conocer varón, su contrario complementario, la Concha, aparece como "la antimujer" hipersexuada y estéril cuya cofradía es "la de la Muerte" (De Lión, 1997:77). Es fundamental además señalar la importancia de las marcas étnicas dentro de la lógica de los contrarios complementarios. Pues en efecto, la Virgen de Concepción es objeto del deseo de todos y cada uno de los hombres del pueblo por el solo hecho de que era ahí "la única ladina" (1997:64); mientras que, por su parte, a pesar de tener "el mismo pelo, la misma cara, los mismos ojos, las mismas pestañas, las mismas cejas, la misma nariz, la misma boca y hasta el mismo tamaño", la Concha se distinguía por el hecho de que "era morena, que tenía chichis, que era de carne y hueso y que, además, era puta” (1997:10).

El gesto del artista indio que disimula su amor y su odio mediante la confección de la efigie de la virgen ladina puede ser visto como una cifra del principio mimético que organiza esa exploración de la subjetividad que es El tiempo principia en Xibalbá. Pues al igual que la del escultor, la mano del escritor talla el velo de palabras que encubre y al mismo tiempo exhibe la "brillante desnudez" de la Virgen de Concepción, modelando en el relato la imagen ambigua de su deseo. Sin duda, se trata de un amor/odio semejante al que Pascual Baeza manifiesta respecto a su pueblo natal, al que percibe como un "pueblo de mierda" que "ni siquiera una calle nueva inventa, ni un nuevo apellido, ni una nueva cara, ni una nueva manera de enamorar, ni de chupar, ni de vestir" (De Lión, 1997:27), pero al cual regresa inevitablemente, atraído por una fuerza ctónica que se manifiesta a través de un vínculo irrenunciable:

vos, el que aquí dejó enterrado su ombligo y se llevó su vida, el que regresó por su ombligo para morir junto a él pero dejó en otro lado su vida [...] sabés que podrías morir en otra parte y querés ser enterrado junto a tu madre, en sus brazos, en sus brazos de polvo, regresar a su matriz de polvo hasta volverte su niño de polvo, su embrión de polvo, hasta la nada de polvo con ella (De Lión, 1997:28).

Además de hacer notar la naturaleza de este deseo -que es literalmente una pulsión de muerte- quisiera señalar la importancia de una variante enunciativa que se puede apreciar en el pasaje citado y que, hasta donde tengo noticia, no ha sido suficientemente puesta de realce por la literatura crítica sobre esta novela, a saber, la utilización sistemática de la segunda persona del singular.

Emilio del Valle considera la utilización de la segunda persona del singular en El tiempo principia en Xibalbá como una forma de autoconsciencia por parte del autor respecto a la heterogeneidad del texto, esto es, respecto al hecho de que su novela estaba dirigida "mayormente a una audiencia ladina”; para Del Valle se trata entonces de un mecanismo destinado a "desconectarnos de la narrativa" y a hacer una pausa que permitiría a Luis de Lión "dirigirse al lector a manera de condenar y denunciar la explotación de mano de obra indígena y el colonialismo" (Del Valle, 2015:332). Creo, por mi parte, que este análisis no tiene en consideración el hecho central de que en esos pasajes el relato prosigue, pero como un relato de vida que los propios personajes hacen de sí mismos y constituye además una forma peculiar de acceso a su conciencia. Esto significa que ahí el narrador, que se ha vuelto intradiegético, "habla consigo mismo", y que la formalidad de su conciencia no está presidida por la unicidad del yo, sino por un desdoblamiento de la enunciación que es correlativo de una escisión del sujeto mismo.

Esta forma de conciencia atañe principal pero no exclusivamente a Pascual Baeza, pues también se puede observar en el caso de Juan Caca. Y es que, en realidad, conforme a la lógica de los contrarios complementarios, Pascual Baeza y Juan Caca son dos facetas antitéticas de un mismo personaje. A pesar de que existe una muestra explícita de ello en el discurso interior de Juan Caca - “Sí, sentís envidia del que se llevó a la Virgen, a la otra Concha, a la verdadera. Sentís envidia porque sabés quién es él, porque sos vos mismo pero al revés, es el diagüevo, 
no el cobarde" (De Lión, 1997:66, énfasis añadido)— quiero poner el énfasis en el hecho de que en ambos casos se trata de una subjetividad migrante, y que ello responde no solo a que ambos han salido del pueblo, sino sobre todo a que ambos comparten el mismo deseo de incorporación étnica.

En efecto, si Pascual "había pasado la frontera y había vivido un tiempo en otro país al que nunca alguno de este pueblo iría ni en sueños", y además "había vivido con una prostituta que nunca le dio un hijo, porque no quería que fuera indio igual a su padre pero a quien él amaba por su color" (De Lión, 1997:46), por su parte Juan Caca siente en su fuero interno envidia de su reverso, del "diagüevo" que rapta a la Virgen de Concepción:

Porque recordás que vos también te enamoraste de ella, que varias veces estuviste tentado a salir de tu aislamiento, de ingresar a la cofradía para que te eligieran principal y tener la oportunidad de llevártela a tu casa. Recordás que [...] ya en tu casa la soñabas desnudita en tu cama, que la sentías, que la oías cesar, acabar, que la probabas y no pensando en si era virgen o madre o puta sino mujer blanca, ladina, mujer de otro lado, de la otra raza a la que vos te querías integrar por tu dinero, por la blancura de tu casa, de tu alma, a pesar de la indiez de tu cara, de tu rabadilla, de tu pelo. Recordás que una vez dijiste que con ella sí tendrías un hijo, un hermano de tu madre del invasor de estas tierras, un divino mestizo aunque después te negara, a vos. Recordás que sabiendo que era imposible una unión con ella, con esa madera, buscaste en la ciudad qué pariente suya podría quererte, que buscaste a muchas, que les decías que en tu pueblo tenías tierras, dinero, buena casa, recordás que todas te rechazaron, que no te miraban siquiera, que sólo te escuchaban las de las cantinas pero que de todas maneras te decían: —indio! (De Lión, 1997:65-66).

El tema central del diálogo que se produce durante la entrevista entre "Gallina" y "Coyote" (un encuentro en registro fabulístico entre Juan Caca y Pascual Baeza), es ni más ni menos que el de la migración. Pero, como señalé anteriormente, aquí la migración está nuclearmente vinculada con un deseo de "integración" que se expresa concretamente como un fantasma de incorporación, cifrado en la posibilidad de concebir, de procrear con una mujer blanca, "de la otra raza":

Linduras abundan en otros lugares. Pero no son tuyas. Lo único que podés hacer es que se te caiga la saliva. Y de repente te juntás con una mujer, una cualquiera pero de un color diferente al tuyo. Y una mujer te da todo lo que puede dar una mujer menos un hijo porque no quiere que ese niño sea como vos (De Lión, 1997:51).

Estos dos personajes constituyen claramente dos principios complementarios (activo/pasivo) de una misma subjetividad. Gallina "ve a Coyote como si fuera su sombra"; se duerme "y se sueña coyote"; y aunque cuando despierta se da cuenta de que "todo es nada más que un sueño porque sigue siendo gallina” (De Lión, 1997:53), el influjo de su contrario complementario induce en él un proceso de metamorfosis subrepticia pero efectiva. Es así como su mujer (la Concha), a quien nunca conoció sexualmente, le hace ver que ya no parece ser el mismo, ante lo que él naturalmente - Gallina al fin - responde con autoengaño, cobardía y negación. "Pero él sabe que está mintiendo, que se está mintiendo, que ya no es el mismo sino sólo un rastro, una huella de lo que ha sido. Pero siente terror de decir la verdad" (1997:53).

Así, en ese pasaje el relato organiza un interesante juego de miradas en el que Gallina, a pesar de intentar "huir de sí mismo", lanza una ambigua mirada a "la cara que está del otro lado del espejo", esa "que lo mira después de la línea divisoria del cristal". Y aun cuando, renuente, "se acercó al espejo pero no quiso mirarse", la mirada proveniente del otro lado del cristal sí lo miraba a él, puesto que constituye el principio activo que induce su metamorfosis en sí mismo: "su sombra", él mismo "pero al revés", es decir Coyote o "el diagüevo". Esta situación especular, que es correlativa de la forma discursiva de la segunda persona del singular, no solo da cuenta de una escisión del sujeto, sino sobre todo del principio mimético gracias al cual los contrarios exhiben su complementariedad mediante el pasaje al acto. En efecto, si Juan Caca descartaba su íntimo, ferviente 
e inconfesable deseo de unirse a la Virgen de madera por considerarlo imposible - al igual que el resto de los varones del pueblo-, Pascual Baeza pasa al acto, realiza la fantasía colectiva:

Entonces, se levantó de la cama, se acercó a ella, procedió a quitarle una a una la ropa, con lentitud, así como podría desnudar un ladino a su mujer la noche del casamiento [...] Durante toda la noche pasó en lucha constante contra la madera, puyándola, queriendo atravezarla [sic] a puro huevo, pero la madera se resistía. A veces parecía que se iba a convertir en carne, que como que estaba a punto de sangrar y entonces, su miembro se volvía más nervio, más miembro, más necio [...] Cuando los gallos cantaron por última vez y la luz y el calor del día empezaron a presentirse por el cerro del Cucurucho, ya no pudo más. Y, ojeroso, desvelado, deshecho su miembro, herido, dolorido, su cara más vieja como si viniera de un lugar terrible, se sentó en la cama y con los ojos semiabiertos, casi a punto de cerrarse al sueño, todavía la miró como quien mira a un enemigo que lo ha derrotado. Pero ella también parecía haber perdido, parecía triste, vieja también, también ojerosa, en sus mejillas ya no había ni sombra de color y sus labios necesitaban ahora de algún colorete para aparentar frescura. Parecía una cualquiera, parecía una puta (De Lión, 1997:60-61).

El pasaje al acto isexual? despoja a la materia de la imagen, y hace que la Virgen aparezca como un "santo de palo", igual a los otros que solo "estaban colgados" (De Lión, 1997:64): San José, obligado a contemplar la profanación "tieso" y "acuernado" desde su camarín, o el Espíritu Santo, que "trataba de salirse de la pintura que lo tenía atado al cuadro" como un espíritu, "no santo sino cualquiera, rojo de envidia" (1997:71). Como se observa, más que hacerlas aparecer como materia inerte o con la gravedad de divinidades mancilladas, el sacrilegio hace que las deidades se muestren deleznables, semejantes a seres humanos pringados de miserias como la impotencia, la envidia, la ira, la vergüenza o la hipocresía:
Entonces, le dio vergüenza y de un tirón se zafó de él, corrió hacia donde estaba su ropa y se puso el vestido blanco, el manto azul, la corona de reina de las vírgenes, de rosa mística, torre de David, arca de oro, salud de los enfermos, refugio de pecadores, etc. Y les pidió perdón a todos, les dijo que disculparan pero que tenía años y años de haber conocido sólo a la paloma y que de allí en adelante nada, que mentiras, que seguía siendo virgen, que gracias porque la perdonaban, que gracias por no hacerle nada a su momentáneo marido, que sí, que déjenlo, que no tuvo la culpa, que había sido ella quien se le había insinuado y que ni modo, él era hombre (De Lión, 1997:72).

De la misma manera en que Pascual realiza — activamente - la fantasía de Juan, a Juan le sucede - pasivamente - la fantasía de Pascual. Si mediante su transgresión este último exhibe la complementariedad entre virgen y puta que se teje en torno a la concepción, destituyendo a la Virgen de su condición de madre colectiva - "Es que ella no es nuestra madre. Ella es una mujer ladina cualquiera" (De Lión, 1997:80) —, Juan es violado por una mujer que llega como en sueños, y que cuando se va deja un rastro de olor que será el señuelo para la consumación de su metamorfosis. Mujer, ella misma, que ha sufrido un proceso de metamorfosis, en tanto que primero era la Concha convertida en virgen, y después resulta ser la madre de Juan, es decir la Muerte coronada: ${ }^{8}$

Entonces, se dio cuenta de un nuevo olor, el olor de algo, de ila mujer?, olor especial que trascendía de los ponchos a la casa, de la casa al corredor, del corredor a la calle.

—No, no fue un sueño. De verdá, una mujer se durmió conmigo.

¿Quién? ¿La Virgen de Concepción que habría vuelto de carne sólo para él? bueno, no le importaba eso ahora. Sólo el olor que lo transformaba en perro en brama. En perro con rabia de brama. Que vinieran todas las mujeres del pueblo. Y la Concha virgen. Y la Concha puta. Pero ahorita. Bueno, mejor después. Ahora iría a buscar a la mujer que lo había violado 
tan ricamente para saborearla otra vez, para agradecérselo.

Se vistió rápidamente. Y se lanzó a la calle. Como un perro el perfume de un hueso, persiguiendo el olor, siguiéndolo, agachándose a cada rato para olfatear la tierra cuando se le perdía, olfateando las piedras, la basura, las pepitas, la mierda, pues ella había puesto su pie sobre las plastas (De Lión, 1997:87).

Metamorfoseado en perro (o icoyote?), Juan Caca se deja conducir rabiosamente por el olor hacia la plazuela del pueblo, en donde lo que era una dualidad se habrá de multiplicar en una jauría. Pues en efecto, ahí Juan Caca se encuentra con todos los demás hombres del pueblo "amontonados, también rabiosos, en brama", y a excepción de él y Pascual, "armados con machetes y pistolas", conformando una "rara procesión" que llevaba en andas ni más ni menos que a su "nana", a su madre.

Así, en conformidad con el principio mimético que le es subyacente, la lógica de los contrarios complementarios muestra cómo Pascual Baeza y sus actos no son sino la faz aparente de lo que resulta ser una fuerza profunda, ctónica, que se manifiesta gracias a la dispersión del sujeto en jauría y a su reorganización en una nueva subjetividad: como procesión y cofradía que celebra y consagra a la puta estéril, a la antimujer (la Muerte) en tanto madre colectiva.

Al realizar el fantasma colectivo de la incorporación étnica, la mimesis novelesca lo priva de su sustancia imaginaria, lo vacía, y con ello disuelve el orden simbólico al que daba sustento el deseo del sujeto colonial. Por lo que en realidad el acto de Pascual no es más que la manifestación aparentemente volitiva de una fuerza profunda, demónica (con la marca del inframundo, de Xibalbá), que destruye/recrea el orden imperante conforme a un tiempo que está también sujeto a la lógica de los contrarios complementarios. Es decir, un tiempo en el que el principio es el fin y viceversa, y en el que se celebran incesantemente la metamorfosis del sujeto colonial y su reintegración en una matriz ctónica, es decir la cancelación de la reproducción asociada con el fantasma de la incorporación.

\section{Subjetividad migrante}

El análisis precedente muestra que en El tiempo principia en Xibalbá la mimesis opera como un mecanismo de desmitificación, cuyo funcionamiento sin duda se asemeja a la "máquina de guerra" que describen Gilles Deleuze y Felix Guattari (1997) en su "Tratado de nomadología". Ahí, los autores de Mil mesetas. Capitalismo y esquizofrenia retoman el análisis de las mitologías indoeuropeas realizado por Georges Dumézil, en particular en lo que se refiere a la estructura de la soberanía y su composición dual, conformada por elementos antitéticos y complementarios (el rey-mago y el sacerdote-jurista) que resultan "necesarios el uno para el otro", pero "sin hostilidad, sin mitología de conflicto”. Y señalan:

sin duda esos dos polos se oponen término a término, como lo oscuro y lo claro, lo violento y lo tranquilo, lo rápido y lo grave, lo terrible y lo regulado, el "lazo" y el "pacto", etc. Pero su oposición tan sólo es relativa; funcionan emparejados, alternativamente, como si expresaran una división de lo Uno o compusieran una unidad soberana (Deleuze y Guattari, 1997:360).

La "máquina de guerra" es el nombre que estos autores otorgan a una agencia de exterioridad radical, irreductible a la lógica de la soberanía evocada por Dumézil, y destinada a conjurar la posibilidad de que los contrarios complementarios operen dialécticamente para conformar un Estado (o, quizás podríamos adelantar, una identidad étnica perfectamente estable o "territorializada"). La máquina de guerra no se reduce a ninguno de esos dos polos, ni tampoco forma un tercero. Más bien:

sería como la multiplicidad pura y sin medida, la manada, la irrupción de lo efímero y potencia de la metamorfosis. Deshace el lazo en la misma medida en que traiciona el pacto. Frente a la mesura esgrime un furor, frente a la gravedad una celeridad, frente a lo público un secreto, frente a la soberanía una potencia, frente al aparato una máquina. Pone de manifiesto otra justicia, a veces de una crueldad incomprensible, pero a veces también de una piedad desconocida (puesto 
que deshace los lazos). Pero sobre todo pone de manifiesto otras relaciones con las mujeres, con los animales, puesto que todo lo vive en relaciones de devenir, en lugar de efectuar distribuciones binarias entre “estados” (Deleuze y Guattari, 1997:360).

No es mi interés establecer una lectura "deleuziana" de El tiempo principia en Xibalbá, sino servirme de las notables semejanzas que es posible percibir entre las funciones de la máquina de guerra descritas por Deleuze y Guattari y el dispositivo mimético aquí analizado, para resaltar la importancia de ese "término de exterioridad" que en nuestro texto sin duda aparece dotado de una función metamórfica y antidialéctica, pero que más que "máquina de guerra" convendría nombrar "subjetividad migrante", en prolongación de las ideas de Cornejo Polar sobre el "sujeto migrante". 9

Como se ha dicho, el personaje Pascual/Juan constituye por sí mismo una subjetividad migrante, en tanto que su apariencia, su actuación y su mirada están profundamente afectadas por su salida del pueblo natal:

Cuando Pascual regresó al pueblo traía, además de los años que lo habían llevado de niño a hombre, una cara como si ya fuera de otra parte; traía en los dientes, en lugar de algunos de ellos, pedazos de oro que trataba de mostrar con orgullo cuando reía o hablaba; traía en la boca palabras raras, desconocidas como de hombre que ha aprendido otros idiomas; traía en los pies zapatos en lugar de caites; traía en la cabeza sombrero de petate y en el cuerpo ropa distinta de la que se usaba en la aldea. Ya no era de aquí. Así parecía (De Lión, 1997:45).

Juan, por su parte, también se fue; y aunque volvió, en cierto modo solo regresó su sombra, pues él se "quedó perdido en otra parte", soñando con ese mundo ajeno a su aldea - "Pensaste, te pensaste internacional y que bien pudiste haber nacido en otra parte de otro padre y no de éste que te había heredado la tierra en que vivís" (De Lión, 1997:35) - . Ahora bien, recordemos que el manifiesto "desapego" de Juan Caca a su heredad, a su tierra, que corresponde directamente a la negación de su padre/madre (la muerte, su muerte), tiene su contraparte en la irrefrenable fuerza de atracción que experimenta Pascual, quien claramente regresa con el deseo de reintegrarse al seno de su madre vuelta polvo. De modo que estamos frente a este personaje dual, que por un lado regresa a su tierra solo como una sombra -habiendo dejado allá, en el exterior y la lejanía, sus sueños y su deseo-, y que sin embargo experimenta en carne propia el furor desatado por el impulso instintivo, visceral, por el cual su contraparte consuma el vaciamiento del fantasma colonial. Como si correlativamente al pasaje al acto de Pascual, a Juan le correspondiera experimentar el "regreso de lo reprimido" de una manera total y avasalladora, que no solo arrastra su subjetividad, sino que incluso destruye el orden simbólico del que esta participa. ${ }^{10}$

La analogía con la máquina de guerra se refuerza además por el hecho de que Pascual "había desertado del ejército con todo y arma, que había estado en la cárcel pero por robo, que había jefeado a una pandilla de ladrones de almacenes, que había integrado otra de cuatreros en la costa, que había entrado otras veces más a la cárcel", e incluso "había estado en una revolución de shute pero había estado" (De Lión, 1997:46); y que para Deleuze y Guattari, desde el punto de vista del Estado, es decir de "la forma de interioridad que habitualmente tomamos como modelo, o según la cual pensamos habitualmente":

la originalidad del hombre de guerra, su excentricidad, aparece necesariamente bajo una forma negativa: estupidez, deformidad, locura, ilegitimidad, usurpación, pecado [...] Dumézil analiza los tres "pecados" del guerrero en la tradición indo-europea: contra el rey, contra el sacerdote, contra las leyes derivadas del Estado (supongamos una transgresión sexual que comprometa la distribución de los hombres y las mujeres, supongamos incluso una traición a las leyes de la guerra tal y como son instituidas por el Estado). El guerrero está en la situación de traicionarlo todo, incluida la función militar, o de no entender nada (Deleuze y Guattari, 1997:361-362). 
En otras palabras, aquí el sujeto migrante aparece bajo la forma de una figura de exterioridad radical, destinada no solo a quebrantar los modos de conocimiento habituales, sino a trastocar de manera raigal la dialéctica de contrarios complementarios sobre la que reposa el orden simbólico. Y aunque Cornejo Polar alertó enfáticamente contra el peligro de incurrir en la celebración "apoteósica de la desterritorialización", es claro que en la obra de Luis de Lión la "condena" que pesa sobre el sujeto migrante y lo orilla a hablar "desde más de un lugar", conforme a un "discurso doble o múltiplemente situado", alcanza una radicalidad que el propio Cornejo no solo entrevió, sino que de hecho nombró - aunque con cierta reserva - ni más ni menos que mediante la misma categoría clínica que Deleuze y Guattari convirtieron en un instrumento crítico para pensar "maquinarias de guerra" como El tiempo principia en Xibalbá:

\begin{abstract}
Mi hipótesis primaria tiene que ver, escribe el crítico peruano, con el supuesto que el discurso migrante es radicalmente descentrado, en cuanto se construye alrededor de ejes varios y asimétricos, de alguna manera incompatibles y contradictorios de un modo no dialéctico. Acoge no menos de dos experiencias de vida que la migración, contra lo que se supone en el uso de la categoría de mestizaje, y en cierto sentido en el del concepto de transculturación, no intenta sintetizar en un espacio de resolución armónica; imagino - al contrario - que el allá y el aquí, que son también el ayer y el hoy, refuerzan su aptitud enunciativa y pueden tramar narrativas bifrontes $y$ - hasta si se quiere, exagerando las cosas - esquizofrénicas (Cornejo, 1996:841).
\end{abstract}

Es claro que, más que de una exageración, en el caso de Luis de Lión conviene hablar de una radicalización de las formas literarias de la subjetividad migrante. Y, sobre todo, de cómo la elucidación de esta exploración literaria se relaciona epistemológicamente con lo que, a través de los métodos correspondientes, han arrojado investigaciones de antropología histórica o cultural, en lo relativo al problema de las subjetividades indí- genas y las categorías de clasificación socio-racial en las sociedades latinoamericanas. Pues en efecto, lo que algunos de esos trabajos muestran es que, desde muy temprano, la categoría de mestizaje resultó un cajón de sastre donde se colocaba todo aquello que no encajara en el esquema de definición importado de España (derivado de la noción de "limpieza de sangre" y de los dualismos que le eran inherentes); y que cuando mucho, el mestizaje pudo haber servido como criterio clasificatorio en el momento más temprano de la colonización, cuando la población estaba compuesta por una aplastante mayoría de aborígenes y un puñado de colonos españoles. Caillavet y Minchom (1992) explican cómo, aunque muy pronto surgió el cuestionamiento relativo a la manera en la que se debía clasificar la creciente diversidad de mestizajes que la misma colonización engendraba, paradójicamente "la solución consistió en ignorarlos y excluirlos de esa construcción ideal, demasiado halagadora como para ser puesta en duda por la minoría en el poder". Lo cual explicaría que esa población "marginalizada" e "inclasificable" fuera objeto de constantes reproches por parte de los colonos blancos; pues según estos autores, en realidad el principal defecto del mestizo era "poner en entredicho, tal como los moriscos y los cristianos nuevos en la metrópolis, la permanencia de una sociedad imaginaria construida a través de duras batallas, ya sea que se trate de la reconquista española o de la conquista de América (Caillavet y Minchom, 1992:120-121, traducción propia).

El mestizaje resulta ser así una categoría inestable, que solo adquirirá el carácter sintético y de "resolución armónica" al que alude Cornejo Polar de manera tardía, como parte de los ajustes realizados por las sociedades republicanas en respuesta a la pérdida de sustento jurídico para legitimar la desigualdad social con base en criterios asociados a la etnicidad. ${ }^{12}$ Entonces, lo que desde una perspectiva histórico-antropológica salta a la vista es que, dentro del cuadro colonial, el mestizaje constituyó un ámbito en el que era posible ejercer diversas estrategias socio-raciales — diferenciadas según el sexo-, como una manera de escapar a la fiscalidad, el derecho penal u otras esferas de coacción externa: 
Si en el ámbito judicial afirmar tener cuatro cuartos de ascendencia indígena era un recurso salvador frente al tribunal de la Inquisición - como el mestizo que se disfrazó de indio en 1636 para engañar al Santo Oficio-, en otro registro, las mujeres mestizas que se dedicaban al pequeño comercio en las calles y mercados podían también encontrar un interés en hacerse pasar por indias y esquivar de esa manera el impuesto a la reventa (alcabala) al que estaba obligada exclusivamente la población blanca. Mediante un acto de prestidigitación inverso, el indio podía por el contrario aducir su mestizaje para escapar al tributo, como en las "Declaraciones de mestizo" instruidas ante la Audiencia de Quito, en las que se despliega un abanico rico en prácticas y estrategias para facilitar la travesía a través de las fronteras socio-raciales: una migración acompañada de un cambio de vestimenta y de nombre, fes de bautismo falsificadas, matrimonios entre miembros de categorías diferentes e incluso el abandono de niños frente a las puertas de los blancos, un procedimiento denunciado por un funcionario de la Corona como una defraudación fiscal (Caillavet y Minchom, 1992:121-122).

Así, más que como el espacio de un supuesto equilibrio dialéctico — propicio para resolver la paradoja de la desigualdad republicana-, el mestizaje debe ser reconocido como un espacio de indeterminación en el que son posibles las más variadas estrategias de mimetismo social y de migración subjetiva, por lo cual la sustitución del mestizaje por el sujeto migrante en tanto categoría del imaginario social tiene como objetivo nombrar esa inestabilidad, esa dimensión de desidentificación cultural.

$\mathrm{Al}$ igual que las dos Concepciones o que Pascual y Juan, y al igual también que el narrador y su refracción en la segunda persona del singular, en la obra de Luis de Lión el sujeto migrante aparece como el doble, como la sombra del "divino mestizo" (1997:66). No solo como su contrario complementario, sino sobre todo como su principio de metamorfosis: como la máquina de guerra que fractura la síntesis dialéctica destinada a hacer permanecer en el imaginario -impensada - la desigualdad republicana. En esa medida, coincido con Emilio del Valle en que:

lo que obtenemos en El tiempo principia en Xibalbá no es un "problema indígena" como usualmente claman muchos escritores indigenistas, lo que existe es más bien un problema mestizo o ladino en este caso. Esta ideología, por ende, debe ser desarticulada e incluso destruida — como se sugiere con la destrucción de la virgen de madera, "la única ladina del pueblo"- para dar lugar a un nuevo proceso de reivindicación y reafirmación que emerja desde el mundo maya. Se trata de mayanizar la nación, así como también de una reapropiación y reescritura de la historia indígena, ya no por los mediadores ladinos o mestizos que clamaban hablar por los indios, sino por los indios mismos. Lión por ende, busca rearticular la cosmogonía del Popol Wuj como un lugar de enunciación político y militante. Esto ya no solo se convierte en la epistemología de un proyecto descolonizador, sino también en la piedra angular de la nación (Del Valle, 2015:333-334).

Sin embargo, este crítico asocia el personaje de Pascual con el autor y asume, sin la mediación del necesario análisis de la relación enunciativa entre el narrador y los personajes, que "[l]a decisión de Pascual de actuar políticamente es también la decisión del autor kaqchiquel de sacrificar su vida en la lucha armada guatemalteca" (Del Valle, 2015:334). Esta extrapolación epistemológica me hace entrever el riesgo de que el examen de la subjetividad "india" llevado a cabo por Luis de Lión sea conducido hacia una resustancialización que ratifique el dualismo étnico que la novela deconstruye. Pues no debemos perder de vista que la crítica —o si se quiere la destrucción simbólica- que ahí se opera no reposa sobre alguna inexistente sustancialidad de lo "indio", sino sobre la potencia de desidentificación del sujeto migrante. Escribe Arturo Taracena:

En materia de relaciones interétnicas, al dividir binariamente a la población guatemalteca en indios y ladinos, el Estado liberal simplificó por obvias razones políticas la complejidad del sistema de castas here- 
dado de la colonia, [que era en sí mismo un intento por categorizar una realidad inclasificable y que] los conservadores habían reducido a un esquema esencialmente trinitario de criollos, ladinos e indios. De esta suerte, pasó a convivir en las esferas estatales una política de segregación hacia las comunidades indígenas y una de asimilación hacia los individuos indígenas que negaban su realidad comunitaria ( $\mathrm{Ta}$ racena, 2019:539). ${ }^{13}$

La novela ensancha el intersticio que se insinúa entre segregación y asimilación, entre "ladinización" y apego comunitario, y convierte el mimetismo del sujeto migrante en una máquina de guerra que opera una desincorporación imaginaria generalizada, esto es, una auténtica quiebra del sistema simbólico. De ahí surge la fuerza ctónica, el tiempo terrible de Xibalbá que sin duda ya nos rige, pero cuyo significado histórico queda aún por dilucidar.

\section{Notas}

${ }^{1}$ Acerca de la correlación entre los movimientos insurreccionales y el terror de Estado como violencia sistémica en Guatemala, ver Figueroa-Ibarra (2019).

${ }^{2} \mathrm{Si}$ bien algunos autores prefieren referirse al título del libro sagrado de los mayas como Popol Wuj, como una manera de marcar gráficamente la reivindicación del carácter fundacional de ese texto por parte de los propios pueblos mayas, he decidido mantener la utilización de la grafía tradicional Popol Vuh, tal y como aparece en la magnífica edición de Laura Sotelo y Michela Craveri (2017).

${ }^{3}$ El siguiente fragmento de Martin Lienhard deja de manifiesto en qué sentido la pertenencia étnica de Luis de Lión subvierte el sistema textual de la que el filólogo suizo denomina "etnoficción" (pero también de la "transculturación" y del indigenismo en general): "Resulta legítimo interrogarse acerca de la pertinencia de un criterio 'étnico' para considerar una práctica literaria que se realiza, de hecho, en el seno de las sociedades de clases ladinas ('mestizas'), regionales (México) o nacionales (México, Guatemala) [...] Queremos adelantar algunos elementos que acreditan la legitimidad del criterio 'étnico'. Todos los narradores implicados inscriben sus textos en el campo de las tensiones entre sociedades ladinas y subsociedades mayanses. Todos coinciden [...] en la estrategia de inventar estructuras narrativas inéditas para la adaptación o el traslado a la escritura de núcleos de supuesto origen indígena. Como se verá, tal estrategia corresponde a la voluntad de superar, por medio de la ficción, el antagonismo entre los sectores ladinos y las colectividades indígenas, obstáculo principal para la constitución de sociedades regionales o nacionales integradas" (Lienhard, 2003:282).

${ }^{4}$ Martin (2005:3) refiere que El tiempo principia en Xibalbá se escribió bajo una consigna formal de circularidad, lo que emparenta esta novela con la "literatura potencial" del "Ouvroir de Littérature Potentielle" (L'Oulipo), pues esta respondía a restricciones semejantes.

${ }^{5}$ Para la discusión relativa a la identidad del copista del Popol Vuh, remito a Himelblau (1989).

${ }^{6}$ Apoyado en un potente arsenal histórico y filológico, Van Akkeren (2003) sostiene una hipótesis contraria a la de Woodruff (2011), pues para él la escritura del Popol Vuh fue la respuesta de un linaje específico (los Nim Ch'okoj) ante la crisis de legitimidad que atravesaba la región a mediados del siglo XVI. Se trataría entonces de un documento de "propaganda política" destinado a la propia comunidad, no a los españoles. Ello hablaría, de cualquier manera, de un fuerte grado de "transculturalidad", por el cual los modos de producción textual coloniales, claramente heterogéneos respecto al antiguo circuito de comunicación maya, habrían sido a tal grado incorporados que se les concibió como un eventual sustento para la tradición misma.

${ }^{7}$ En ese mismo sentido, cabe recordar que Pascual lleva ese nombre por haber nacido el 2 de noviembre, Día de los Fieles Difuntos. Sin embargo, su madre decide no llamarlo Difunto Baeza sino Pascual, "que es lo mismo que muerto sólo que vivo porque es nombre de santo" (De Lión, 1997:39). Por su parte, en un pasaje posterior Juan vuelve a confrontarse con el espejo todavía "con miedo, sin mirarse todavía". Pero cuando "creyó que ya estaba todo él del otro lado, entonces atravezó [sic] los ojos para saludarlo, para que lo saludaran, para que le 
dijeran que no tuviera pena, que estaba $\mathrm{El}$ con $\mathrm{El}$ acompañándolo. Pero del otro lado sólo estaban sus huesos, sólo su calavera recién muerta, con algunos pedazos de carne todavía, pero muy mínimos, a penas retacitos podridos" (1997:98). Es pues evidente que el proceso de metamorfosis de Juan culmina cuando se transforma enteramente en el que está del otro lado del espejo, es decir en Difunto.

${ }^{8}$ El texto señala explícitamente en un pasaje anterior: “Al fin te acordaste de que tenías padres. Que necesitaban una su flor, una su cruz. Lo que no sabés es que a quien adornaste fue a tu único padre, a tu única madre: la muerte, tu muerte" (De Lión, 1997:35-36).

${ }^{9}$ En uno de sus textos postreros, Cornejo plantea la necesidad de explorar los discursos y modos de representación asociados con la migración, para "producir una categoría que permita leer amplios e importantes segmentos de la literatura latinoamericana", en particular aquellos "que están definidos por su radical heterogeneidad". Pues, aunque "son varias las categorías que se han usado para dar razón de este enredado corpus [...], algunas como la de mestizaje parecen haber agotado en sí toda su capacidad iluminadora”. Es por ello que Cornejo deseaba explorar la pertinencia y la efectividad de la categoría de sujeto migrante, guiado por la sospecha de que "los contenidos de multiplicidad, inestabilidad y desplazamiento que lleva implícitos, y su referencia inexcusable a una dispersa variedad de espacios socioculturales que tanto se desparraman cuanto se articulan a través de la propia migración, la hacen especialmente apropiada para el estudio de la intensa heterogeneidad de buena parte de la literatura latinoamericana" (Cornejo, 1996:838).

${ }^{10}$ A ese respecto, quisiera citar en extenso un pasaje de lapidaria elocuencia: "De pronto", reza el texto, la Muerte "se quitó la corona, la capa, el vestido y, antes de meterse a la pila, por un instante se volvió a ver tal cual era, con toda su mirada de lodo más vacía que negra, con todos sus huesos fragmentados como blanco alambrado de púas y con todo lo mejor que tenía: el pozo de su sexo que era la única parte de carne, de carne negra en donde los presentes desearon hundirse para desde allí ver el otro mundo y ahogarse y podrirse.
Sin embargo, había sido tan rápido su estriptis que pocos pudieron verla y entonces, goteando semen los maduros y los jóvenes, y los más viejos, orines en lugar de semen, empezaron, primero a empujarse para ocupar el lugar más cercano a la pila, y después, sacando machetes y escopetas, empuñando las manos, agarrando piedras y palos, formando grupos de padres contra hijos, de compadres contra compadres, de hermanos contra hermanos, de amigos contra amigos, se pusieron a pelear como bestias, mientras que el agua, asesinada de pronto por un calor frío, primero, perdió definitivamente su color de cielo y después se convirtió en huesos de agua hasta que finalmente sólo fue polvo de huesos de agua, cuya ceniza la dispersó el aire, quedándose la pila como si fuera una tumba que todavía no ha tenido adentro ni un solo cadáver" (De Lión, 1997:78).

11 "Los mestizos escapan al determinismo étnico por dos razones principales: la variabilidad de su estatus puesto que al cabo de dos o tres generaciones ya se pierda la memoria de la mezcla inicial y generalmente el mestizo se acriolla; la otra razón es que los mestizos nunca formaron una 'nación', en el sentido colonial del término, es decir, una comunidad específica con sus derechos y sus deberes, sus divisas, sus vestidos y sus mitos de origen, como los indios, los españoles y los africanos [...] Se dice de los mestizos que están 'apartados y desviados'. Ejercen ocupaciones que implican por lo general movilidad y mediación. Pueden indianizarse o fundirse en la masa urbana" (Bernand, 2006:13).

${ }^{12}$ En su estudio sobre la relación entre "raza" y estructura social en el Perú (y más particularmente en la ciudad de Lima), Jesús A. Cosamalón plantea que, aunque es evidente que el pasado colonial tuvo una influencia decisiva en el origen y evolución de la sociedad peruana, aquel periodo "no fue, al contrario de lo que pueda parecer, el tiempo en el cual existió la mayor rigidez en cuanto a la relación entre esos factores". Más bien, sugiere este historiador, "podemos establecer un derrotero desde, por un lado, una sociedad colonial en la cual el factor racial (calidad) fue concebido hasta mediados del siglo XVIII como una definición legal antes que biológica, que ejerció de ese modo un papel importante en la construcción de las jerarquías sociales, pero no consolidó al 
color de piel, o su percepción, como el marcador definitivo. Por otro lado, tenemos una sociedad republicana donde ese factor legalmente desapareció, pero se reconstituyó, basado esta vez en su relación con la ciencia (racismo científico), el honor (ilegitimidad, matrimonio y trabajo), la riqueza (propiedad, modo de vida), o la cultura (costumbres incivilizadas), proceso que fue consolidado, esta vez sí, en la percepción del color de piel" (2017:36-38).

${ }^{13}$ En el Antiguo Régimen, explica Pérez Navarro, la población indígena "pronto fue asimilada como un estrato socioétnico claramente definido y en detrimento de su propia diversidad. Fue la formación de una población de talante muy heterogéneo la que implicó los ajustes de legislación mayores en busca de mantener restringidos los límites entre los diversos estratos sociales [...] La noción de calidad fue amplísima y permitió su empleo como herramienta para abrir huecos en la estructura social; con el tiempo, convirtió el sistema de estratificación en una estructura voluble, negociable (Pérez, 2017:140).

\section{Referencias}

Bernand, Carmen (2006). "De lo étnico a lo popular: circulaciones, mezclas, rupturas". Nuevo Mundo Mundos Nuevos. Disponible en http://journals.openedition. org/nuevomundo/1318 (consultado el 19 de febrero de 2020).

Bubnova, Tatiana (2002a). "El canon agredido, o la voz de nuevo ressentiment cultural (El tiempo principia en Xibalbá de Luis de Lión)”. En William Mejías López (ed.), Morada de la palabra: homenaje a Luce y Mercedes López-Baralt. San Juan: Editorial de la Universidad de Puerto Rico, pp. 292-322.

Bubnova, Tatiana (2002b). “Más allá de la 'etnoficción', o cuando el otro habla". En Esther Cohen y Ana María Martínez de la Escalera (coords.), Lecciones de extranjería. Una mirada a la diferencia. México: UNAM, Siglo XXI, pp. 154-168.

Caillavet, Chantal y Martin Minchom (1992). "Le métis imaginaire: idéaux classificatoires et stratégies socio-raciales en Amérique Latine (XVIe-XXe siècle)». En L'Homme, 32(122-124), 115-132.
Cornejo Polar, Antonio (1996). "Una heterogeneidad no dialéctica: sujeto y discurso migrantes en el Perú moderno". En Revista Iberoamericana, LXII(176-177), juliodiciembre, 837-844.

Cornejo Polar, Antonio (2003). Escribir en el aire. Ensayo sobre la heterogeneidad socio-cultural en las literaturas andinas. Lima: Celacp, Latinoamericana.

Cosamalón Aguilar, Jesús A. (2017). El juego de las apariencias. La alquimia de los mestizajes y las jerarquías sociales en Lima. Siglo XIX. México: El Colegio de México, Instituto de Estudios Peruanos.

De Lión, Luis (1997). El tiempo principia en Xibalbá. Guatemala: Artemis Edinter.

Del Valle Escalante, Emilio (2015). "Nacionalismo maya y descolonización política: Luis de Lión y El tiempo principia en Xibalbâ". En Cuadernos de Literatura, XIX(38), julio-diciembre, 318-337.

Deleuze, Gilles y Félix Guattari (1997). Mil mesetas. Capitalismo y esquizofrenia (Juan Vázquez Pérez, trad.), Valencia: Pre-textos.

Figueroa-Ibarra, Carlos (2019). "Guatemala: el recurso del miedo". En Ana Silvia Monzón (coord.), Antología del pensamiento crítico guatemalteco contemporáneo. Buenos Aires: CLACSO, pp. 271-284.

Himelblau, Jack (1989). "The Popol Vuh of the Quiche Maya of Guatemala: Text, Copist, and Time Frame of Transcription". En Hispania, 72(1), 97-122.

Liano, Dante (2018). “El tiempo principia en Xibalbá': la primera edición y el manuscrito definitivo. Semejanzas y diferencias". En Centroamericana, 28(2), 57-74

Lienhard, Martin (2003). La vozy su huella. México: Juan Pablos, Unicach.

Martin, Laura (2005). "Luis de Lión y la persistencia de la tradición retórica maya”. En Memorias del Congreso de Idiomas Indígenas de Latinoamérica-II. Austin: Universidad de Texas. Disponible en https://ailla. utexas.org/sites/default/files/documents/Martin CILLA2_deleon.pdf (consultado el 26 de febrero de 2020).

Palacios, Rita M. (2011). "El tiempo principia en Xibalbá and the Foundation of a Contemporary Indigenous Literature in Guatemala". En Revista Canadiense de Estudios Hispánicos, 35(3), 577-595. 
Pérez Navarro, Mónica (2017). “Cultura política en el Antiguo Régimen: Distinción, políticas de segregación y conquista de espacios de interpelación en la Nueva España”. En Revista de El Colegio de San Luis, 13, enerojunio, 132-154.

Sotelo, Laura Elena y Michela Craveri (2017). "Presentación”, En Popol Vuh (Michela Craveri, trad.), México: UNAM.
Taracena, Arturo (2019). "Guatemala: del mestizaje a la ladinización, 1524-1964”, En Ana Silvia Monzón (coord.), Antología del pensamiento crítico guatemalteco contemporáneo. Buenos Aires: CLACSO, pp. 517-544.

Van Akkeren y Ruud W. (2003) "Authors of the Popol Wuj.” En Ancient Mesoamerica, 14(2), 237-256.

Woodruff, John M. (2011). "Ma(r)king Popol Vuh”. En Romances Notes, 51(1), 97-106. 